\title{
A bibliometric analysis of papers published in the South East Asia Journal of Public Health from 2011 to 2015
}

\author{
Md. Anwarul Azim Majumder' ${ }^{1}$, Sayeeda Rahman ${ }^{2}$, Ahbab Mohammad Fazle Rabbi ${ }^{3}$, \\ Palash Das ${ }^{4}$
}

${ }^{1,2}$ Lecturer, Department of Clinical Sciences, School of Medical Sciences, University of Bradford, West Yorkshire, Bradford, UK. ${ }^{3}$ Lecturer, Department of Mathematics and Statistics, Bangladesh University of Textiles, Dhaka, Bangladesh. ${ }^{4}$ Associate Professor, Department of Community Medicine, College of Medicine and Sagore Dutta Hospital, Kolkata, West Bengal, India.

\begin{abstract}
South East Asia Journal of Public Health (SEAJPH) is a Bangladesh-origin, open access and peer reviewed international journal. This study conducted a bibliometric analysis of papers published in the SEAJPH from 2011 to 2015 using data extracted from the Bangladesh Journal Online database. Five volumes (which include eight issues) with a total of 108 papers were included in the analysis. The highest number of papers were published in 2012 and the average number of papers published per year was 21.6. More than $58 \%$ of published papers were original research, followed by short communications $(12.96 \%)$. The highest proportion of papers were published during the study period by single authors $(20.37 \%)$ or three authors $(20.37 \%)$, followed by double authors $(19.44 \%)$. he maximum of average authors/article was found to be 4 in the year 2011, and the minimum was 2.6 in the year 2015 . The degree of collaboration in SEAJPH is approximately 0.80 , and the collaboration was consistently high every year (ranges from 0.74 to 0.87 ). The maximum number of papers was published by professionals from India $(35.16 \%)$, followed by Bangladesh (25\%) and the UK (13.89\%). Timely and accurate evidence-based information from health-related research/publications provide the extent and burden health problems/challenges of countries and regions. AS the SAARC region has the greatest total disease burden of any region in the world and relevant public health research and dissemination/collaboration of findings is crucial to alleviate this burden. The SEAJPH is successful in this regard. However, the journal needs indexing to popular search engines (e.g. PubMed) to attract global researchers and eventually lead to an increase in the citation of the papers.
\end{abstract}

Keywords: Bibliometric analysis, Paper productivity, Authorship pattern, SEAJPH, Bangladesh.

\section{Introduction}

South East Asia Journal of Public Health (SEAJPH) is the official journal of the Public Health Foundation, Bangladesh (PHFBD). The journal is an open access and peer reviewed international journal. The contents of the journal are freely available without charge to the users or their institutions. The main aim of SEAJPH is to provide an intellectual platform for international scholars in the field of public health, health care and medicine. SEAJPH aims to promote interdisciplinary studies in public health and become the leading journal in the field of public health in South East Asia.

The journal welcomes papers on the theory and practice of the whole spectrum of public health across the domains of quality of health, health development, health promotion and prevention, community health, occupational health, health ethics, health economics, health care management, international health, mental health, and clinical sciences from health professionals and researchers. We are committed to promote the highest standards of public health practice nationally, regionally and internationally through the timely dissemination of the best, most recent evidence-based public health research so that the highest quality of healthcare can be provided to the population.

\section{Practice Points}

- Bibliometrics refers to the analysis of the structure of literature using various tools, counting, rank-frequency distributions, and citation analysis.

- In the SEAJPH, more than $58 \%$ of published papers are original research from 2011 to 2015 , and the highest proportion of papers were published by single authors $(20.37 \%)$ or three authors $(20.37 \%)$.

- The degree of collaboration in SEAJPH is approximately 0.80 , and the collaboration was consistently high every year (ranges from 0.74 to 0.87 ).

- The maximum number of papers was published by professionals from India $(35.16 \%)$, followed by Bangladesh (25\%) and the UK (13.89\%).

- Timely and accurate evidence-based information from health-related research/ publications provide the extent and burden health problems/challenges of countries and regions.

Correspondence: Dr. Md Anwarul Azim Majumder, Lecturer, Department of Clinical Sciences, School of Medical Sciences, Faculty of Life Sciences, University of Bradford, Bradford BD7 1DP, West Yorkshire, UK. E-mail: a.a.majumder@bradford.ac.uk. 
Bibliometrics is defined as the analysis of the structure of literature using various tools, counting, rank-frequency distributions, and citation analysis. ${ }^{1}$ It serves a variety of purposes e.g. determination of different indicators, evaluation of output, monitoring and analysis of information resources, management of knowledge and forecasting the potential of a particular field. $^{2}$ This study adopted bibliometric methods to examine paper productivity of SEAJPH from 2011 to 2015 using data extracted from the Bangladesh Journal Online database.

\section{Materials and Methods}

We conducted a bibliometric scrutiny to analyze the bibliographic attributes of the papers published in the SEAJPH from 2011-2015. The data was extracted from the Bangladesh Journal Online database and have been taken up for analysis. The study analyzes the year-wise distribution of papers, category-wise distribution of papers, number of authorship, degree of collaboration, and geographical distribution of contributions.

The degree of collaboration is an examination of the prominent area of inquiry in bibliometric studies, indicating the trend in patterns of single and multiauthorship in the publication. ${ }^{2,3}$ To determine the degree of collaboration in quantitative terms, the following formula is used: ${ }^{4}$

\section{$\mathrm{C}=\mathrm{NM} / \mathrm{NM}+\mathrm{NS}$}

Where,

C - Degree of Collaboration

NM - Number of multi authored articles

NS - Number of single authored articles

\section{Results}

Five volumes (which include eight issues) with a total of 108 papers were published during 2011 to 2015 in SEAJPH. The rejection/withdrawn rate of the papers was $12.2 \%$. Table 1 displays the total number of papers published in the journal. The highest number of papers were published in 2012 and the average number of papers published per year was 21.6. The category-wise distribution of papers published is shown in Figure 1. More than $58 \%$ of published papers are original research, followed by short communications (12.96\%).

Figure 2 reveals that the highest proportion of papers were published during the study period by single authors $(22 / 20.37 \%)$ or three authors (22/20.37\%), followed by double authors $(21 / 19.44 \%)$, and more than five authors (19/17.59\%). The maximum of average authors/article was found to be 4 in the year 2011, and the minimum was 2.6 in the year 2015 (Table 1). The degree of collaboration in SEAJPH is approximately 0.80 (ranges from 0.74 to 0.87 ; Table 1 ), which clearly

Table 1: Annual distribution of papers in the SEAJPH (2011-15)

\begin{tabular}{|c|c|c|c|c|c|c|}
\hline \multirow[t]{2}{*}{ Year } & Issue 1 & Issue 2 & \multirow[t]{2}{*}{ Total papers (\%) } & \multirow{2}{*}{$\begin{array}{c}\text { Numbers of } \\
\text { authors }\end{array}$} & \multirow{2}{*}{$\begin{array}{c}\text { Average } \\
\text { author/article }\end{array}$} & \multirow{2}{*}{$\begin{array}{c}\text { Degree of } \\
\text { collaboration }\end{array}$} \\
\hline & \multicolumn{2}{|c|}{ Number of papers } & & & & \\
\hline 2011 & 15 & - & $15(13.89 \%)$ & 60 & 4 & 0.87 \\
\hline 2012 & 15 & 16 & $31(28.7 \%)$ & 102 & 3.29 & 0.81 \\
\hline 2013 & 15 & 12 & $27(25 \%)$ & 85 & 3.15 & 0.74 \\
\hline 2014 & 14 & 11 & $25(23.15 \%)$ & 88 & 3.52 & 0.80 \\
\hline 2015 & 10 & - & $10(9.26 \%)$ & 26 & 2.6 & 0.80 \\
\hline Total & 69 & 39 & $108(100 \%)$ & 361 & 3.34 & 0.80 \\
\hline
\end{tabular}

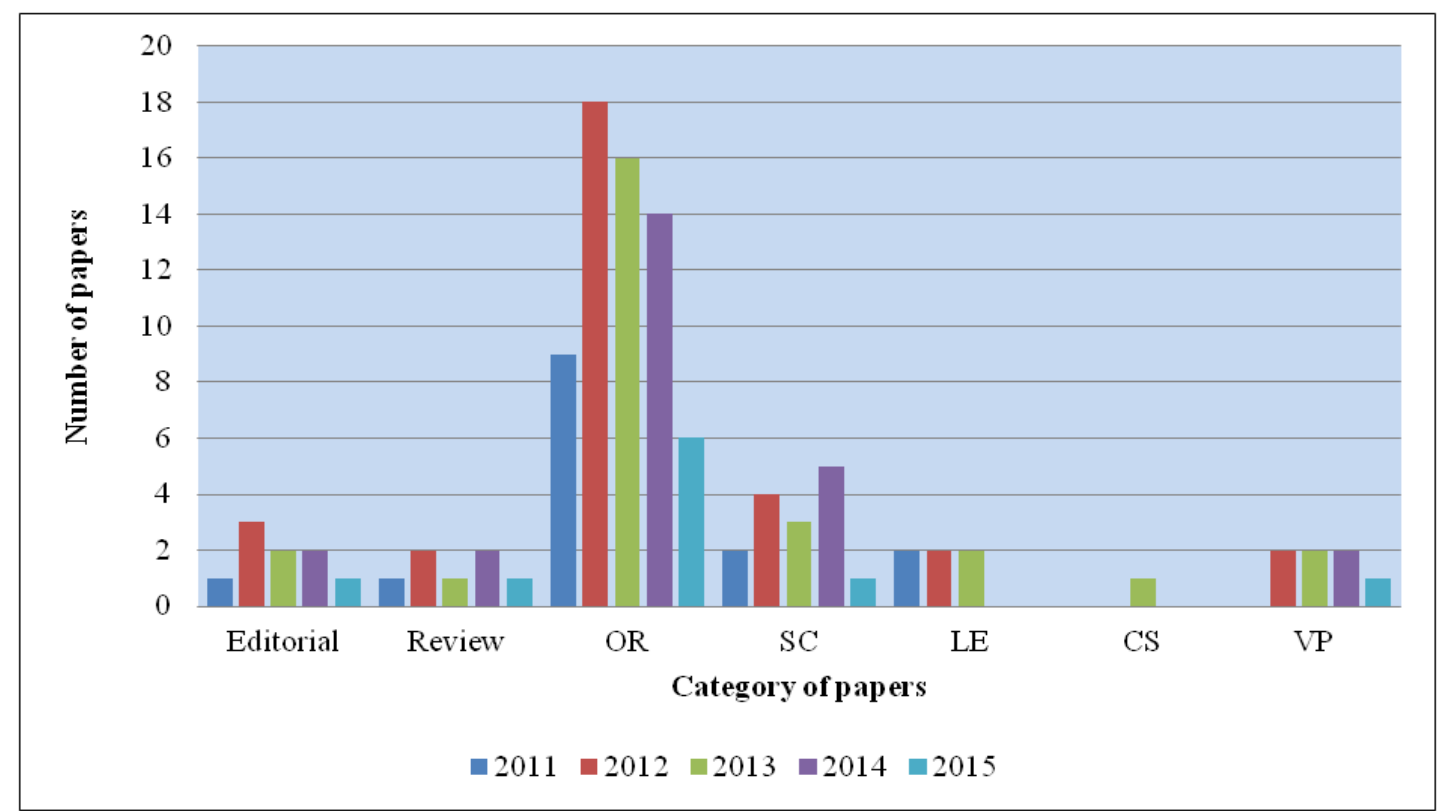

Figure 1: Categories of papers published in SEAJPH (2011-15). OR: Original research; SC: Short communication; LE: Letter to editor; CS: Clinical Sciences: VP: View point 


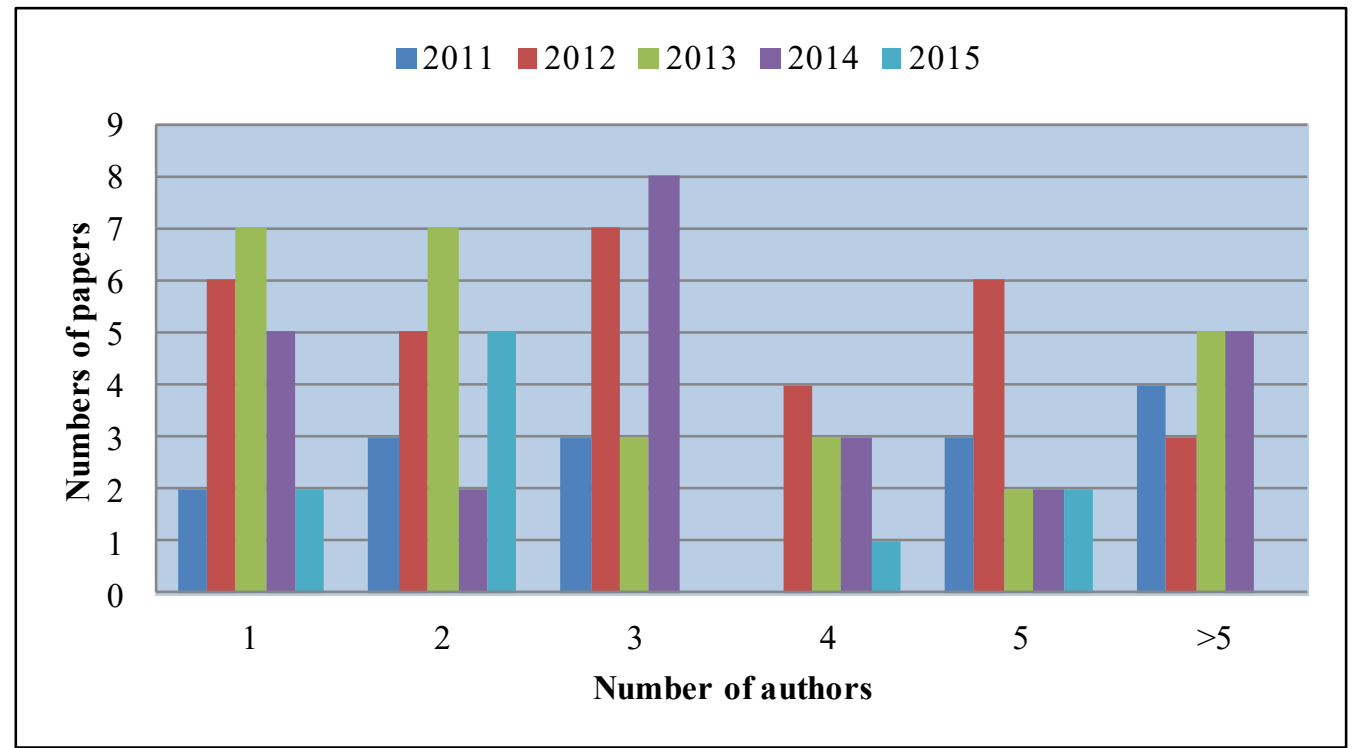

Figure 2: Authorship pattern in the SEAJPH (2011-15)

indicates its dominance upon single authored contributions.

The level of contribution from different countries is shown in Figure 3. The maximum number of papers was published by professionals from India (35.16\%), followed by Bangladesh (25\%), the UK (13.89\%), Malaysia (5.56\%) and Sri Lanka (4.63\%).

\section{Discussion}

This bibliometric study has shed light on the publication practice of SEAJPH from 2011 to 2015. It was found that a total of 108 papers were published during 2011 to 2015 in SEAJPH and average number of papers published per year is 21.6 . More than half $(58 \%)$ of the published papers were original research and one-fifth of papers were published by single author $(20.37 \%)$ or three authors (22/20.37\%), and the average author/ article was 3.34 .

The total degree of collaboration is approximately 0.80 , which shows that more articles were a result of contribution from a collaboration of two or more authors than from single authors. Moreover, the collaboration was found to be consistently high every year (ranging from 0.74 to 0.87 ). Mishre found a degree of collaboration of 0.783 in the Health and Population: Perspective and Issues journal published from India. ${ }^{2}$

The finding of the study also indicates that more than one-third $(35.16 \%)$ of the papers were published by researchers from India, followed by researchers from Bangladesh, who contributed a quarter $(25 \%)$ of the

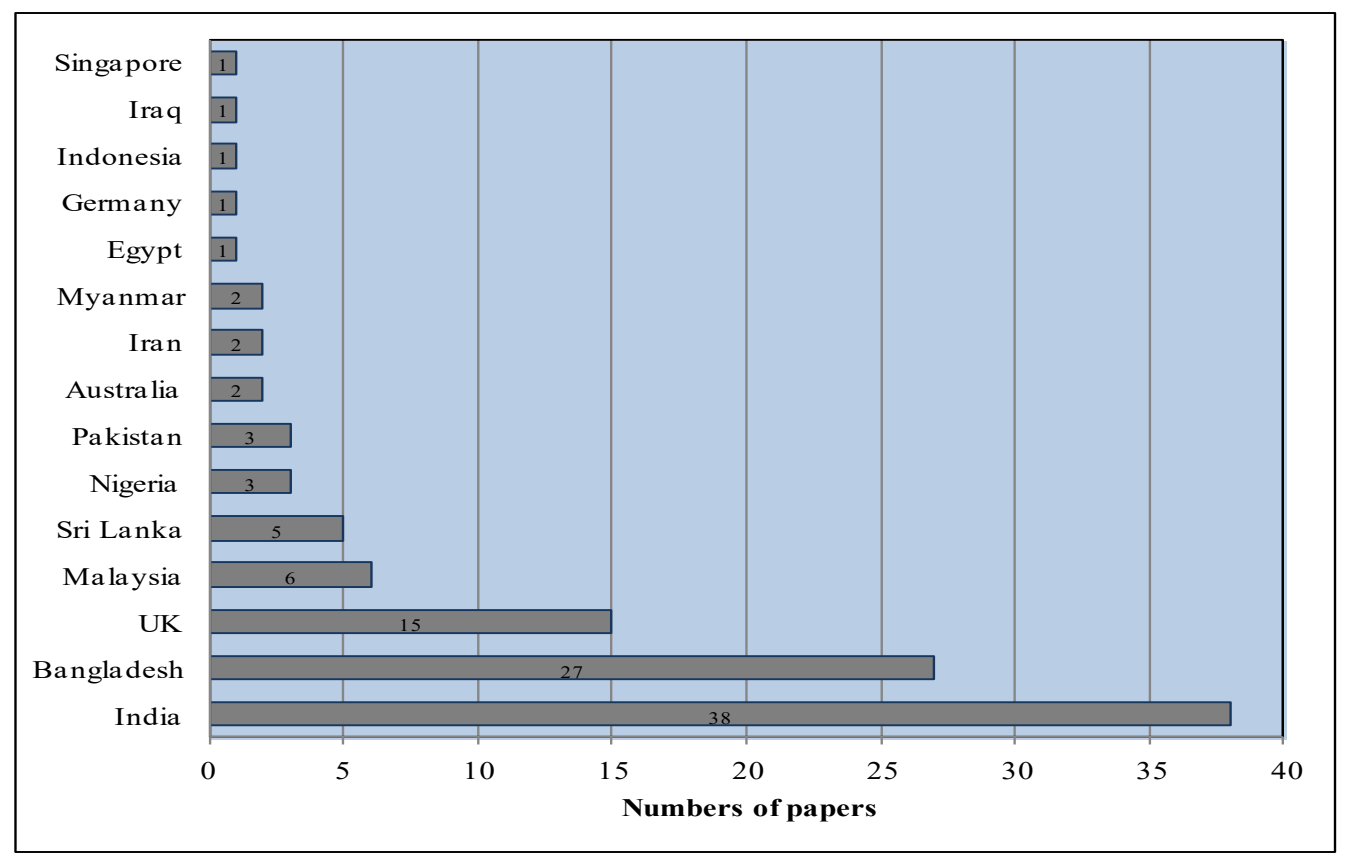

Figure 3: Contribution of different countries in SEAJPH (2011-15) 
publications. This is not surprising as our earlier research showed that India alone produced $90.5 \%$ of the total publications generated by SAARC countries between 1985 and 2009. ${ }^{5}$

Timely and accurate evidence-based information from health-related research/publications provide the extent and burden health problems/challenges of countries and regions. ${ }^{6}$ This information helps to formulate policies, set priorities and use the limited healthcare resources to effectively and efficiently increase the quality of life of the population. ${ }^{6}$ Though SEAJPH is a Bangladeshiorigin journal, $75 \%$ of the papers were from fourteen countries other than Bangladesh, 10 of which countries were outside of the SAARC region. A bibliometric study $^{2}$ of a Indian journal showed that only 4 foreign papers $(1.57 \%)$ were published in 10 years $(2000-2010)$. Another study from India identified that, between 2006 and $2009,23.72 \%$ of the papers in the Indian Journal of Experimental Biology were published by foreign authors. ${ }^{7}$ A bibliometric analysis of the Journal of the Pakistan Medical Association from 2009 to 2013 found that $28 \%$ of the papers were from 12 foreign countries. ${ }^{8}$ The international outlook of the SEAJPH provides the opportunity for the researchers of the region to share/ disseminate their research findings and also learn from researchers of other countries. Our previous research ${ }^{4}$ showed that SAARC countries published $1.1 \%$ of the total papers indexed by PubMed over the last 25 years (1985-2009). AS the SAARC region has the greatest total disease burden of any region in the world and relevant public health research and dissemination/ collaboration of findings is crucial to alleviate this burden. The SEAJPH is successful in this regard.

Medical education in South-East Asian countries is experiencing difficulties in providing the right quality and quantity of educational experiences, ${ }^{10}$ and research in medical education is also in its infancy in the region. ${ }^{11}$ Research showed that only $7 \%$ of papers published in four renowned journals from were from Asian countries. ${ }^{10}$ Educational research influences health care in many ways. Publication of relevant research will provide policymakers evidence-based information to increase the relevance, quality, costeffectiveness and equality of medical education and practice in Asia. Sixteen (14.81\%) papers were published in the SEAJPH which discussed various issues and priorities of health professional education and the provision of need-based education to meet public health challenges.

\section{Conclusion}

This bibliometric analysis showed that SEAJPH published various categories of research papers from different countries of the world and disseminated public health findings to a wider audience. The contents of the SEAJPH are currently indexed by Bangladesh Journal Online which helps to increase the visibility of the papers; however indexing to other popular search engines (e.g. PubMed) will attract global researchers and eventually lead to an increase in the citation of the papers.

\section{References}

1. Hertzel DH. Bibliometrics History. In: Dreke MA. editor. Encyclopedia of information science. Second edition. New York: Marcel Dekker, Inc., 2003, p 288-328.

2. Mishra A. Bibliometric Analysis of the Health and Population: Perspectives and Issues (HPPI) Journal during Year (2000-2010). Libr Philos Pract (e-journal) 2014; Paper 1199.

3. Maharana RK, Sethi BB. A bibliometric analysis of the research output of Sambalpur University's publication in ISI Web of Science during 200711. Libr Philos Pract (e-journal). 2013; Paper 926.

4. Subramanyam K. Bibliometric studies of research collaboration: A review. J Inform Sci 1983;6(1):33.

5. Majumder MAA, Rahman S, Shaban SF, N Rahman, Islam Z. A PubMed-Based Quantitative Analysis of Biomedical Publications in the SAARC Countries: 1985-2009. J Coll Physicians Surg Pak 2012;22:1-7.

6. Majumder MAA, Shaban SF, Rahman S, Ahmed M. Biomedical research productivity in Bangladesh (1996-2010): A comparison with low-income economy. South East Asia J Public Health 2012;2(1):70-2.

7. Baby K, Kumaravel JPS. Indian Journal of Experimental Biology: A Bibliomeric Analysis. SALIS J Informa Manage Tech 2011;2(1):1-9.

8. Ibrahim M, Jan SU. Bibliometric analysis of the Journal of Pakistan Medical Association form 2009 to 2013. J Pak Med Assoc 2015;65(9):97883.

9. Dandona L, Raban MZ, Guggilla RK, Bhatnagar A, Dandona R. Trends of public health research output from India during 2001- 2008. BMC Med 2009;7:59.

10. Majumder MAA, D'Souza U, Rahman S. Trends in Medical Education: Challenges and Directions for Need-based Reforms of Medical Training in South-East Asia. Indian J Med Sci 2004;58 (9):369-80.

11. Majumder MAA. Issues and Priorities of Medical Education Research in Asia. Ann Acad Med Singapore 2004;33:257-63. 